\title{
Evaluation of the incidence, risk factors, and impact on patient outcomes of postintubation hemodynamic instability
}

\author{
Robert S. Green, BSc, MD* ${ }^{\star \ddagger}$; Janet Edwards, BSc, MD ; Elham Sabri, MSc ${ }^{\ddagger 1 I}$; \\ Dean Fergusson, MHA, $\mathrm{PhD}^{ \pm \|}$
}

\section{ABSTRACT}

Objectives: Postintubation hemodynamic instability (PIHI) is a potentially life-threatening adverse event of emergent endotracheal intubation. The objectives of this study were to determine the incidence, risk factors, and impact on patient outcomes associated with $\mathrm{PIHI}$ in intubations performed in emergency medicine.

Methods: A structured chart audit was performed of all consecutive adult patients requiring emergent endotracheal intubations over a 16-month period at a tertiary care emergency department (ED). Data collection included medications, comorbidities, vital signs in the 30 minutes before and after intubation, hospital length of stay, and in-hospital mortality. PIHI was defined as a decrease in systolic blood pressure (SBP) to $\leq 90 \mathrm{~mm} \mathrm{Hg}$, a decrease in SBP of $\geq 20 \%$ from baseline, a decrease in mean arterial pressure to $\leq$ $65 \mathrm{~mm} \mathrm{Hg}$, or the initiation of any vasopressor medication at any time in the 30 minutes following intubation.

Results: Overall, 218 patients intubated in the ED were identified, and 44\% (96 of 218) developed PIHI. On multivariate analysis, increasing age (OR $1.03,95 \% \mathrm{Cl} 1.01-1.05)$, chronic obstructive pulmonary disease (OR 3.00, Cl 1.197.57), and pre-emergent endotracheal intubation hemodynamic instability (OR 2.52, 95\% Cl 1.27-4.99) were associated with the development of PIHI. The use of a neuromuscular blocking medication was associated with a decreased incidence of PIHI (OR 0.34, 95\% Cl 0.16-0.75).

Conclusions: Based on our data, postintubation hypotension occurs in a significant proportion of ED patients requiring emergent airway control. Further investigation is needed to confirm the factors we found to be associated with PIHI and to determine if $\mathrm{PIHI}$ is associated with increased morbidity and mortality.

\section{RÉSUMÉ}

Objectifs: L'instabilité hémodynamique après intubation (IHAI) est un effet indésirable qui peut mettre la vie en danger lors d'une intubation trachéale d'urgence. Cette étude visait à établir l'incidence, les facteurs de risque, et les répercussions sur les résultats pour les patients associés à I'IHAI lors d'une intubation en médecine d'urgence.

Méthodes: Une vérification structurée des dossiers a été effectuée pour tous les patients adultes consécutifs ayant nécessité une intubation trachéale $d$ 'urgence sur une période de 16 mois dans un service des urgences (SU)_de soins tertiaires. Les données recueillies portant notamment sur les médicaments, les comorbidités, et les signes vitaux dans les 30 minutes précédant et suivant I'intubation, la durée de I'hospitalisation, et le taux de décès à I'hôpital. L'IHAI a été définie comme une diminution de la tension artérielle systolique (TAS) à $\leq 90 \mathrm{~mm} \mathrm{Hg}$, une diminution de la TAS de $\geq 20 \%$ par rapport à la référence de base, une diminution de la tension artérielle moyenne à $\leq 65 \mathrm{~mm} \mathrm{Hg}$, ou l'administration de tout médicament vasopresseur à n'importe quel moment dans les 30 minutes suivant l'intubation.

Résultats: Au total, 218 patients intubés au SU ont été identifiés et $44 \%$ (96 sur 218 ) ont présenté une IHAI. D'après une analyse à plusieurs variables, l'augmentation de l'âge (RIA 1,03, IC $95 \%$ 1,01-1,05), la maladie pulmonaire obstructive chronique (RIA 3,00, IC 1,19-7,57), et l'instabilité hémodynamique après intubation trachéale d'urgence (RIA $2,52,95 \%$, IC 1,27-4,99) étaient associées à la présence d'IHAI. L'utilisation de médicaments de blocage neuromusculaire était associée à une diminution de l'incidence de I'IHAI (RIA 0,34, IC 95 \% 0,16-0,75).

Conclusions: D'après nos données, une hypotension après intubation se produit chez beaucoup de patients au SU nécessitant un dégagement des voies respiratoires d'urgence. D'autres recherches doivent être effectuées pour confirmer les facteurs associés à I'IHAl et pour établir si I'IHAI

From the *Department of Emergency Medicine, Dalhousie University, Halifax, NS; tDivision of Critical Care Medicine, Department of Anesthesia, Dalhousie University, Halifax, NS; ‡Ottawa Center for Transfusion Research, Ottawa, ON; §Department of Surgery, University of Calgary, Calgary, AB; and IIOttawa Health Research Institute, Ottawa, ON.

Correspondence to: Dr. Robert S. Green, Room 377 Bethune Building, 1276 South Park Street, Halifax, NS, B3H 2 Y9.

This article has been peer reviewed 
est reliée à une augmentation de la morbidité et de la mortalité.
Keywords: adverse events, airway, epidemiology, hypotension, intubation
Emergent endotracheal intubation (EETI) is a common and potentially lifesaving procedure in critically ill patients. ${ }^{1-3}$ Physicians often use a systematic approach during resuscitation, with the assessment and stabilization of a patient's airway and respiratory system as a primary focus. ${ }^{4,5}$ Various strategies to support the respiratory system are available, with EETI being the most frequent technique used in the critically ill population. ${ }^{3,6-8}$

When compared to non-EETI, EETI is associated with a high rate of adverse events (AEs). ${ }^{9-15}$ AEs range from relatively minor in nature (oral tissue and dental trauma) to serious and life threatening (e.g., bradycardia, hypoxemia, hypotension, cardiac arrest, and death). ${ }^{11,12}$ Postintubation hemodynamic instability (PIHI) is a common $\mathrm{AE}$ in emergent airway management, yet its association with clinically important outcomes such as mortality, organ dysfunction, and hospital length of stay (LOS) has not been demonstrated, despite data indicating that hypotension in the critically ill patient population increases morbidity and mortality. ${ }^{16-18}$

PIHI has been variably reported in studies of intubations in the emergency department (ED). Based on available data, the incidence of PIHI during EETI ranges from 0.0 to $38.6 \% . .^{14,19-22}$ In addition, little is known about factors associated with the development of PIHI, which may be of importance when determining management strategies for EETI in the ED.

The primary objective of this study was to determine the incidence of PIHI in adult patients requiring EETI at a tertiary academic ED. The secondary objective was to determine the risk factors associated with the development of PIHI and the association of PIHI with patient mortality and hospital LOS.

\section{METHODS}

\section{Study design}

This was a retrospective, standardized chart review of consecutive ED patients requiring intubation.

\section{Study setting and population}

The study population included all consecutive patients requiring EETI at the Queen Elizabeth II Health
Sciences Centre ED, Halifax, Nova Scotia, between March 1, 2004, and July 1, 2005. The Queen Elizabeth II Health Sciences Centre ED is an adult (age $\geq$ 16 years) tertiary care ED with approximately 70,000 patient visits per year and serves as a referral centre for the provinces of Nova Scotia, New Brunswick, and Prince Edward Island.

Inclusion criteria were all adult patients ( $\geq 16$ years) managed by an attending emergency physician or supervised trainees who required EETI. EETI was defined as the passage of an endotracheal tube through a patient's glottis via either the oral or nasal route in any patient intubated in the ED. Exclusion criteria included pediatric patients ( $<16$ years), patients who only required noninvasive positive pressure ventilation for support of the respiratory system, patients in whom a surgical airway was required without an initial attempt at endotracheal intubation, or intubation prior to arrival in the ED. All methods of endotracheal intubation were eligible for inclusion.

\section{Measurements}

As no standard definition of PIHI was available, the steering group developed a definition of PIHI based on expert opinion and published definitions. An iterative process was employed with presentations at national meetings (Canadian Critical Care Trials Group [CCCTG]) and teleconferences (Critical Illness Airway Management [CLAM] Group) until consensus was achieved for the definition of PIHI. PIHI was defined as any decrease in systolic blood pressure (SBP) to $\leq 90 \mathrm{~mm} \mathrm{Hg}$, a reduction in SBP of $20 \%$ from baseline, a decrease in mean arterial pressure (MAP) to $\leq 65 \mathrm{~mm} \mathrm{Hg}$, or the initiation of a vasopressor medication at any time in the 30 minutes following EETI. Baseline SBP was defined by the average of all SBP values observed in the 30 minutes prior to EETI. ${ }^{13-15,19,20,22-31}$ Preintubation hypotension was defined as an average $\mathrm{SBP} \leq 90 \mathrm{~mm} \mathrm{Hg}, \mathrm{MAP} \leq$ $65 \mathrm{~mm} \mathrm{Hg}$ in the 30 minutes prior to EETI, or the use of a vasopressor medication (bolus or infusion). Transient PIHI was defined as meeting any PIHI criterion on a single occasion during the 30 -minute post-EETI study period, whereas sustained PIHI was 
defined as meeting any PIHI criterion for the entire duration of the 30-minute study period.

Blood pressure measurements were recorded from invasive (arterial catheter) or noninvasive means, which included both automated and nonautomated devices. All blood pressure measurements available in the medical record for the 30 minutes before and after intubation were extracted. Blood pressure measurement timing was not protocolized during resuscitations in the study centre.

Assessed patient outcomes were also determined by expert opinion (authors, members of the CLAM Group and the CCCTG) and included in-hospital mortality, hospital LOS, and hospital discharge location.

\section{Study protocol}

Patients were identified by manual review of a standardized ED intubation clinical database capturing ED admissions requiring intubation, in addition to a review of admission logs from the medical/surgical intensive care units $(n=2)$, coronary care unit $(n=1)$, and cardiovascular intensive care unit $(n=1)$. All ED patients who required intubation at the study hospital were admitted to one of these four areas. After patient identification, the medical record was manually reviewed by one of the investigators (J.E., nonblinded), and patients who met the eligibility criteria were retained. The data abstractor underwent training prior to data acquisition, including database instruction, electronic medical record instruction, and practice data retrieval, under the supervision of the senior author (R.S.G.) prior to initiation of the study. Data were abstracted into a standardized, computerized intubation database developed by the authors with input from experts in EETI. Data extraction variables included demographic data, patient comorbidities, and outpatient medications. Patient data were recorded for at least 30 minutes before and after intubation (if available) and included vital signs (e.g., blood pressure, heart rate, and oxygen saturations) and medications used for EETI. In addition, the in-hospital mortality and discharge location were also recorded. Data not recorded in the medical record were coded as missing and not imputed. All data were extracted by a single investigator (J.E.), and $10 \%$ of the medical records were selected at random and reviewed by a second investigator (R.S.G.) for accuracy using the selected clinical variables of blood pressure, vasopressor use, hospital LOS, and in-hospital mortality. Discrepancies were resolved by consensus at prespecified data quality control meetings.

\section{Data analysis}

The baseline characteristics of included patients were assessed in terms of age, sex, comorbidities, ED diagnosis, and preintubation hypotension, stratified by the presence or absence of PIHI. The frequency of medications administered in the 30 minutes prior to EETI was also reported for the entire cohort and stratified by the presence or absence of PIHI.

Multivariable logistic regression analysis was performed to determine risk factors associated with the development of PIHI. Variables were determined a priori based on clinical experience and expert opinion. The effect of age, sex, comorbidities, number of intubation attempts, level of provider, and medications received in the 30 minutes prior to EETI were assessed in this multivariable analysis. Age was entered as a continuous variable in the model as a satisfactory linear pattern was demonstrated by plotting the estimated logits of the response variable (PIHI) versus the predictor variable (age). Multicollinearity was assessed by examining the variance inflation factor (VIF) using linear regression analysis, with all VIF values being less than 2.5. The adequacy of the model was confirmed with calculation of the $\mathrm{C}$ statistic $(77.1 \%)$ and the Hosmer-Lemeshow goodness-of-fit test $(p$ value $=$ $0.67)$.

The in-hospital and ED mortality rates were calculated for both PIHI and non-PIHI patients and compared using the chi-square test. The median LOS in hospital was the difference between the admission and the hospital discharge date and was compared between the two groups with the Wilcoxon-MannWhitney test. The association of PIHI with in-hospital mortality and hospital LOS was also assessed after adjustment for effect of age, sex, chronic obstructive pulmonary disease (COPD), and the use of a paralytic medication during EETI.

\section{Ethics}

The study was approved by the Capital District Health Association Research Ethics Board, Halifax, Nova Scotia. 


\section{RESULTS}

Overall, 78,811 patients presented over 16 months to the study hospital ED, of whom 218 patients $(0.28 \%)$ met eligibility and were included for analysis. The mean age of the study sample was 56.5 years, and $39 \%$ were female. Table 1 outlines patient comorbidities and the ED diagnosis, and Table 2 documents medications administered to facilitate EETI in the 30 minutes prior to intubation. Overall, $67.9 \%$ of patients received neuromuscular blocking medications for EETI. Other commonly used medications were propofol (39.5\%), benzodiazepines (28.9\%), etomidate $(25.7 \%)$, opioids (19.7), and ketamine $(10.5 \%)$.

The incidence of PIHI was 44\% (96 of 218 patients). The proportions of patients meeting individual criteria for the definition of PIHI are outlined in Table 3. All 218 patients were included in the analysis. On multivariable analysis, increasing age (OR 1.03, 95\% CI 1.01-1.05), COPD (OR 3.00, 95\% CI 1.19-7.57), and pre-EETI hemodynamic instability (OR $2.52,95 \%$ CI 1.27-4.99) were associated with the development of PIHI (Table 4).

The use of a paralytic medication during EETI was associated with a decreased incidence of PIHI (OR
$0.34,95 \%$ CI 0.16-0.75). No other medication used to facilitate EETI, including propofol, benzodiazepines, opioids, etomidate, and ketamine, was associated with the development of PIHI. When propofol dosage was considered ( $\geq 140 \mathrm{mg} \mathrm{v} .<140 \mathrm{mg}$ ), higher dosages were not associated with the development of PIHI (OR 2.33, 95\% CI 0.29-5.17).

The in-hospital mortality rate for the study group was $25.7 \%$ and was increased in patients who developed PIHI (34\%, 33 of 96) compared to those who did not $(19 \%, 23$ of 122$)$ (crude OR 2.25, 95\% CI 1.244.19). After adjustment for baseline risk factors captured in the PIHI multivariable analyses (age, sex, COPD, and the use of a paralytic medication during EETI), the odds ratio of in-hospital mortality associated with PIHI was equal to 1.41 (95\% CI $0.71-$ 2.82). Similarly, mortality in the ED was increased in the PIHI group $(11 \%$ v. $4 \% ; p=0.039$; crude OR 3.03, 95\% CI 1.01-9.04; adjusted OR 1.91, 95\% CI 0.59-6.19) (Table 5). Patients who developed sustained PIHI had increased mortality compared to those who had transient PIHI (Table 6). Patients who developed PIHI also had an increased median hospital LOS (17 v. 9 days, $p=0.004)$. However, after adjustment for baseline factors (e.g., age, sex, COPD, and the use of neuromuscular blocking agent), the development of

\begin{tabular}{|c|c|c|c|}
\hline & No PIHI & $\mathrm{PIHI}$ & Overall \\
\hline & $(n=122)$ & $(n=96)$ & $(N=218)$ \\
\hline Mean age (SD) & $50.8(19.8)$ & $63.8(19.4)$ & $56.5(20.62)$ \\
\hline Sex, $(F),(\%)$ & $42(34.4)$ & $43(44.8)$ & 85 (38.99) \\
\hline \multicolumn{4}{|l|}{ Comorbidities, $n(\%)$} \\
\hline COPD & $9(7.4)$ & $25(26)$ & $34(15.6)$ \\
\hline Diabetes & $25(20.5)$ & $28(29.2)$ & $53(24.3)$ \\
\hline Ischemic heart disease & $15(12.3)$ & $18(18.7)$ & $33(15)$ \\
\hline Hypertension & 40 (32.8) & $38(39.6)$ & 78 (35.8) \\
\hline \multicolumn{4}{|l|}{ Diagnosis, ${ }^{*} n(\%)$} \\
\hline Central nervous system & $10(8.8)$ & $4(4.9)$ & $14(7.2)$ \\
\hline Cardiovascular & $7(6.2)$ & $17(20.9)$ & $24(12.4)$ \\
\hline Infection & $13(11.5)$ & $13(16)$ & $26(13.4)$ \\
\hline Intra-abdominal catastrophe & $6(5.3)$ & $5(6.2)$ & $11(5.7)$ \\
\hline Toxic ingestion & $23(20.3)$ & $10(12.3)$ & $33(17)$ \\
\hline Metabolic & $5(4.4)$ & $1(1.2)$ & $6(3.1)$ \\
\hline Respiratory failure & $11(9.7)$ & $10(12.3)$ & $21(10.8)$ \\
\hline Trauma & $26(23)$ & $11(13.6)$ & $37(19.1)$ \\
\hline Other & $12(10.6)$ & $10(12.3)$ & $22(11.3)$ \\
\hline Pre-EETI hypotension, $n(\%)$ & $26(21.3)$ & $40(41.7)$ & 66 (30.3) \\
\hline
\end{tabular}




\begin{tabular}{|c|c|c|c|}
\hline & No PIHI & $\mathrm{PIHI}$ & Overall) \\
\hline Medication & $(n=122)$ & $(n=96)$ & $(N=218$ \\
\hline Propofol, $n(\%)$ & $53(43.4)$ & $33(34.4)$ & $86(39.5)$ \\
\hline Etomidate, $n(\%)$ & $31(25.4)$ & $25(26)$ & $56(25.7)$ \\
\hline Benzodiazepine, $n(\%)$ & $36(29.5)$ & $27(28.1)$ & $63(28.9)$ \\
\hline Midazolam & $28(22.9)$ & $20(20.8)$ & $48(22)$ \\
\hline Lorazepam & $9(7.4)$ & $8(8.3)$ & $17(7.8)$ \\
\hline Diazepam & $4(3.3)$ & $2(2.1)$ & $6(2.7)$ \\
\hline Opioids, $n(\%)$ & $24(19.7)$ & $19(19.8)$ & $43(19.7)$ \\
\hline Fentanyl & $22(18)$ & $15(15.6)$ & $37(17)$ \\
\hline Morphine & $2(1.6)$ & $4(4.1)$ & $6(2.7)$ \\
\hline Hydromorphone & 0 & 0 & 0 \\
\hline Ketamine, $n(\%)$ & $13(10.7)$ & $10(10.4)$ & $23(10.5)$ \\
\hline Neuromuscular blocking medications, $n(\%)$ & $95(77.9)$ & $53(55.2)$ & $148(67.9)$ \\
\hline Succinylcholine & $80(65.6)$ & $43(44.8)$ & $123(56.4)$ \\
\hline Rocuronium & $15(12.3)$ & $12(12.5)$ & $27(12.4)$ \\
\hline Other (vecuronium/atracurium/pancuronium) & $1(0.8)$ & $2(2.1)$ & $3(1.4)$ \\
\hline Vasopressor medications, $^{\dagger} n(\%)$ & $6(4.9)$ & $11(11.5)$ & $17(7.8)$ \\
\hline
\end{tabular}

PIHI was not found to be associated with an increased hospital LOS $(p$ value $=0.114)$ or mortality $(\mathrm{OR} 1.41$, 95\% CI 0.71-2.82).

\section{DISCUSSION}

This is the first study to assess the incidence, risk factors, and corresponding association of PIHI with patient adverse outcomes. Our data indicate that PIHI is common in critically ill patients in our ED as $44 \%$ of patients who required intubation developed PIHI within 30 minutes after intubation. Increasing age, COPD, and pre-EETI hemodynamic instability were associated with the development of PIHI; interestingly, the use of a neuromuscular blocking agent was associated with a decreased incidence of PIHI. Despite the incidence of PIHI, when baseline factors were controlled for in multivariable analysis, PIHI was not associated with increased mortality or hospital LOS.

Endotracheal intubation is considered a cardinal, lifesaving procedure and is a common strategy in the resuscitation of critically ill patients with various pathophysiologic states. ${ }^{2,4,5}$ Despite the importance of EETI, its impact on patient outcome and associated AEs has not been well documented. The incidence of PIHI varied widely in previous studies, ranging from 0.0 to $38.6 \% .{ }^{13-15,19-31}$ Some studies of AEs in EETI failed to evaluate PIHI, and those that did suffer from the lack of a standard definition of PIHI. ${ }^{19,20,25-29,32-35}$

\begin{tabular}{|c|c|}
\hline Criterion & $n(\%)$ \\
\hline $\mathrm{PIHI}$ & $96 / 218(44)$ \\
\hline a. Any $\mathrm{SBP} \leq 90$ within 30 min of EETI & $55 / 218(26)$ \\
\hline b. Any MAP $\leq 65$ within 30 min of EETI & $35 / 218(17)$ \\
\hline c. Any decrease in SBP $\geq 20 \%$ of baseline within 30 min of EETI & $70 / 218(32)$ \\
\hline d. The initiation of or increase in infusion of any vasopressor within 30 min of EETI ${ }^{\dagger}$ & $30 / 218(14)$ \\
\hline \multicolumn{2}{|c|}{$\begin{array}{l}\text { EETI = emergent endotracheal intubation; MAP = mean arterial pressure; PIHI = postintubation hemodynamic instability; SBP = systolic } \\
\text { blood pressure. } \\
\text { *Patients may have met more than one criterion for PIHI. }\end{array}$} \\
\hline
\end{tabular}




\begin{tabular}{|c|c|c|c|c|}
\hline & Odds ratio & $95 \%$ cor & ce limits & $p$ value \\
\hline Age & 1.03 & 1.01 & 1.05 & 0.0041 \\
\hline Sex (F v. M) & 1.64 & 0.87 & 3.11 & 0.1289 \\
\hline \multicolumn{5}{|l|}{ Comorbidities } \\
\hline Pre-EETI hemodynamic instability & 2.52 & 1.27 & 4.99 & 0.0079 \\
\hline COPD & 3.00 & 1.19 & 7.57 & 0.0198 \\
\hline Diabetes & 1.27 & 0.58 & 2.76 & 0.5491 \\
\hline Ischemic heart disease & 0.98 & 0.41 & 2.34 & 0.9562 \\
\hline Hypertension & 0.91 & 0.43 & 1.92 & 0.8084 \\
\hline \multicolumn{5}{|l|}{ Medications used to facilitate EETI } \\
\hline Propofol & 1.40 & 0.62 & 3.17 & 0.4230 \\
\hline Etomidate & 1.38 & 0.53 & 3.56 & 0.5079 \\
\hline Opioids & 1.26 & 0.58 & 2.74 & 0.5600 \\
\hline Benzodiazepine & 1.12 & 0.55 & 2.27 & 0.7451 \\
\hline Neuromuscular blocking agent & 0.34 & 0.16 & 0.75 & 0.0077 \\
\hline \multicolumn{5}{|l|}{ Technical intubation skills } \\
\hline Number of intubation attempts (> 1 v. 1) & 1.65 & 0.65 & 4.16 & 0.2910 \\
\hline \multicolumn{5}{|l|}{ Level of provider } \\
\hline Resident v. physician & 1.30 & 0.64 & 2.64 & 0.4597 \\
\hline Other v. physician & 1.27 & 0.46 & 3.52 & 0.6390 \\
\hline
\end{tabular}

Therefore, the wide range of PIHI previously reported may be due to the variable definitions of PIHI, in addition to a focus on other AEs, such as the success of tracheal intubation, mainstem bronchi intubation, esophageal intubation, and airway trauma.

We found a high incidence of PIHI when compared to previous ED studies. Franklin and colleagues also sought to describe the incidence of postintubation hypotension and found that $28.6 \%$ of patients intubated in the ED developed PIHI. ${ }^{13}$ Lin and colleagues recently described their experience in Taiwan and found an incidence of PIHI of $18.8 \% .{ }^{31}$ In addition, PIHI has been described in non-ED settings, with a range of 9.6 to $38.6 \% .^{14,21,22}$ Numerous reasons may have resulted in the high rate of PIHI that we found in our study. First, the definition of PIHI used in our study may be more logical, clinically relevant, and therefore sensitive than those used in previous investigations. In fact, it is difficult to assess the impact of our definition, which was developed by the research team based on previous studies and expert opinion. Second, our data abstraction included all vital signs available in the 30 minutes prior to and after intubation, which allows for rigorous assessment of hemodynamic instability. Finally, the incidence of PIHI found in our study may be due to our systematic focus on this primary outcome, whereas the majority of previous studies have reported $\mathrm{PIHI}$ in a less rigorous manner.

\begin{tabular}{|c|c|c|c|}
\hline & No PIHI & $\mathrm{PIHI}$ & \\
\hline & $(n=122)$ & $(n=96)$ & $p$ value \\
\hline Died in ED, ${ }^{*} n(\%)$ & $5(4)$ & $11(11)$ & Chi-square test: 0.039 \\
\hline Died in hospital, ${ }^{\dagger} n(\%)$ & $23(19)$ & $33(34)$ & Chi-square test: 0.009 \\
\hline LOS in hospital, ${ }^{\ddagger}$ days (SD) & $9(5,18)$ & $17(7,34)$ & Wilcoxon test: 0.004 \\
\hline \multicolumn{4}{|c|}{$\begin{array}{l}\text { ED = emergency department; LOS = length of stay; PIHI = postintubation hemodynamic instability; SD = standard deviation } \\
\text { *Patient expired in the ED after emergent endotracheal intubation. } \\
\text { tPatient expired during hospital stay. } \\
\text { F } \\
\text { fLOS data were summarized using the median (interquartile range). Patients who died in hospital were excluded from this calculation; four } \\
\text { patients had missing discharge dates and were excluded from the LOS calculations. }\end{array}$} \\
\hline
\end{tabular}




\begin{tabular}{|c|c|c|c|}
\hline & Transient $\mathrm{PIHI}{ }^{\dagger}$ & Sustained $\mathrm{PIHI}^{\ddagger}$ & Overall \\
\hline Patients, $n(\%)$ & $62(68)$ & $29(32)$ & 91 \\
\hline PIHI duration, median (IQR) & $7.5(0-55)$ & 70 (30-166) & $30(0-80)$ \\
\hline Death, $n(\%)$ & $16(26)$ & $13(45)$ & $29(32)$ \\
\hline
\end{tabular}

Common opinion dictates that medications used for EETI in critically ill patients contribute to hemodynamic instability. ${ }^{24,30,36,37}$ However, we were unable to identify a clear association between medications used to facilitate intubations in our patients and the incidence of PIHI. Interestingly, we found no association (protective or otherwise) with the use of etomidate for EETI and PIHI. We also found that patients who received neuromuscular blocking medications for EETI were less likely to develop PIHI. This is intriguing as it is common practice for emergency physicians to use neuromuscular blocking medications, yet this practice remains a controversial issue in anesthesia practice. ${ }^{38}$ Emergency physicians often use neuromuscular blocking medication to facilitate EETI, citing the fact that muscle relaxation allows for optimal intubation conditions. The mechanism for this association is unclear as neuromuscular blocking medications do not have a known effect on blood pressure. Given this, similar research needs to be performed to confirm the accuracy of our findings as our small sample size limits definitive conclusions on the impact of medications on PIHI.

We also found that pre-EETI hemodynamic instability was an important factor associated with the development of PIHI. Interestingly, this has not previously been described, although the exacerbation of systemic hemodynamic instability by EETI in a critically ill patient may not be a surprise to many clinicians. Although we are unsure of the specific association of pre-EETI hemodynamic instability with PIHI, this point serves to highlight the impact of EETI on the physiologic status of this patient population. It is possible that pre-EETI resuscitation in an attempt to optimize physiologic stability prior to EETI would result in less PIHI, yet this remains to be demonstrated by future investigation.

The impact of PIHI on patient morbidity and mortality has also not been previously investigated.
In our patients, PIHI was not associated with increased mortality or increased ED or hospital LOS when baseline factors were controlled for, despite higher ED and hospital mortality in patients who developed PIHI. Interestingly, a previous investigation demonstrated increased mortality in patients who developed hypotension in the ED. ${ }^{16}$ Indeed, it may be expected that patients requiring EETI are a selected subpopulation of physiologically compromised individuals in whom further hemodynamic instability is likely poorly tolerated and that mortality may be increased. Although our study did not demonstrate a mortality hazard in patients who develop PIHI after controlling for baseline factors, we cannot exclude PIHI as an AE of EETI that impacts on patient survival. Our finding that sustained PIHI was associated with increased mortality supports this position. A larger sample size would be required to further investigate the association of PIHI with patient outcomes.

We also found a number of factors that may be associated with PIHI, including increasing age and COPD. COPD and cardiovascular dysfunction have been described previously. ${ }^{13,14,31}$ These data may indicate that it is possible that patients at risk for PIHI can be identified prior to EETI, therefore allowing planning for the immediate management of this $\mathrm{AE}$. Further research is required to confirm these findings.

\section{LIMITATIONS}

We suggest caution in the interpretation of our study. Although we found that neuromuscular blocking medications are associated with a decreased incidence of PIHI, further study is required to determine direct cause and effect. Our retrospective study design does not allow us to determine a causal link. We view these results as preliminary and reason to fuel future research into a potentially important quality of care issue. Overall, the number of patients receiving any given 
medication is relatively small; therefore, our findings on the impact of medications on the incidence of PIHI require confirmation. We noted that patients with preEETI received less propofol, fewer opioids, and more etomidate during EETI. Although our analysis controlled for differences in medications used to facilitate EETI, it is possible that residual confounding exists. Other limitations of our study include data from a single academic centre and the lack of standardized vital sign recording in the patients' medical records. Data on the degree of difficulty of intubation and the method of blood pressure measurement, along with other variables, were not fully documented in the medical record. It is also possible that all intubations at our centre were not included in the study. However, this is unlikely as multiple ED and hospital databases were used to systematically identify patients. Finally, although our definition was developed based on physiologic rationale, clinical experience, expert consensus, and examples from the literature, it is possible that it is oversensitive. Hypotension that occurs beyond 15 to 25 minutes may not be associated with EETI, which would be one scenario in which our definition of PIHI is oversensitive. Similarly, our definition of pre-EETI blood pressure (average of blood pressure over 30 minutes prior to EETI) was chosen to best reflect the overall patient physiologic status prior to EETI and was determined by expert opinion based on information available in the literature. However, at present, there is little information to either support or refute these issues, and only further research and refinement of our definition will allow for better understanding of this $\mathrm{AE}$.

\section{CONCLUSION}

Based on our data, postintubation hypotension occurs in a significant proportion of ED patients requiring emergent airway control. Further investigation is needed to confirm the factors we found to be associated with PIHI and to determine if PIHI is associated with increased morbidity and mortality.

Competing interests: None declared.

\section{REFERENCES}

1. Kharasch M, Graff J. Emergency management of the airway. Crit Care Clin 1995;11:53-66.

2. Mort TC. Anesthesia practice in the emergency department: overview, with a focus on airway management. Curr
Opin Anaesthesiol 2007;20:373-8, doi:10.1097/ACO.0b013e 32825 eabe7.

3. Shuster M, Nolan J, Barnes TA. Airway and ventilation management. Cardiol Clin 2002;20:23-35, doi:10.1016/ S0733-8651(03)00063-8.

4. Part 4: Advanced life support. Circulation 2005;112(22 Suppl):III-25-54.

5. Diamond LM. Cardiopulmonary resuscitation and acute cardiovascular life support - a protocol review of the updated guidelines. Crit Care Clin 2007;23:873-80, vii, doi:10.1016/ j.ccc.2007.08.001.

6. Walz JM, Zayaruzny M, Heard SO. Airway management in critical illness. Chest 2007;131:608-20, doi:10.1378/chest.062120.

7. Langeron O, Amour J, Vivien B, Aubrun F. Clinical review: management of difficult airways. Crit Care 2006;10:243, doi:10.1186/cc5112.

8. Idris AH, Gabrielli A. Advances in airway management. Emerg Med Clin North Am 2002;20:843-57, ix, doi:10.1016/ S0733-8627(02)00031-7.

9. Fasting S, Gisvold SE. Serious intraoperative problems-a five-year review of 83,844 anesthetics. Can $\mathcal{F}$ Anaesth 2002; 49:545-53, doi:10.1007/BF03017379.

10. Domino KB, Posner KL, Caplan RA, Cheney FW. Airway injury during anesthesia: a closed claims analysis. Anesthesiology 1999;91:1703-11, doi:10.1097/00000542199912000-00023.

11. Mort TC. Complications of emergency tracheal intubation: immediate airway-related consequences: part II. 7 Intensive Care Med 2007;22:208-15, doi:10.1177/0885066607301359.

12. Mort TC. Complications of emergency tracheal intubation: hemodynamic alterations-part I. F Intensive Care Med 2007; 22:157-65, doi:10.1177/0885066607299525.

13. Franklin C, Samuel J, Hu TC. Life-threatening hypotension associated with emergency intubation and the initiation of mechanical ventilation. Am 7 Emerg Med 1994;12:425-8, doi:10.1016/0735-6757(94)90053-1.

14. Jaber S, Amraoui J, Lefrant JY, et al. Clinical practice and risk factors for immediate complications of endotracheal intubation in the intensive care unit: a prospective, multiple-center study. Crit Care Med 2006;34:2355-61, doi:10.1097/ 01.CCM.0000233879.58720.87.

15. Reid C, Chan L, Tweeddale M. The who where, and what of rapid sequence intubation: prospective observational study of emergency RSI outside the operating theatre, Emerg Med 7 2004;21:296-301.

16. Jones AE, Yiannibas V, Johnson C, Kline JA. Emergency department hypotension predicts sudden unexpected inhospital mortality: a prospective cohort study. Chest 2006; 130:941-6, doi:10.1378/chest.130.4.941.

17. Lalezarzadeh F, Wisniewski P, Huynh K, et al. Evaluation of prehospital and emergency department systolic blood pressure as a predictor of in-hospital mortality. Am Surg 2009;75:1009-14.

18. Schreiber MA, Aoki N, Scott BG, Beck JR. Determinants of mortality in patients with severe blunt head injury. Arch Surg 2002;137:285-90, doi:10.1001/archsurg.137.3.285.

19. Sakles JC, Laurin EG, Rantapaa AA, Panacek EA. Airway management in the emergency department: a one-year study 
of 610 tracheal intubations. Ann Emerg Med 1998;31:325-32, doi:10.1016/S0196-0644(98)70342-7.

20. Tayal VS, Riggs RW, Marx JA, et al. Rapid-sequence intubation at an emergency medicine residency: success rate and adverse events during a two-year period. Acad Emerg Med 1999;6:31-7, doi:10.1111/j.1553-2712.1999.tb00091.x.

21. Griesdale DE, Bosma TL, Kurth T, et al. Complications of endotracheal intubation in the critically ill. Intensive Care Med 2008;34:1835-42, doi:10.1007/s00134-008-1205-6.

22. Mort TC. Emergency tracheal intubation: complications associated with repeated laryngoscopic attempts. Anesth Analg 2004;99:607-13, doi:10.1213/01.ANE.0000122825. 04923.15 .

23. Dufour DG, Larose DL, Clement SC. Rapid sequence intubation in the emergency department. 7 Emerg Med 1995; 13:705-10, doi:10.1016/0736-4679(95)00089-S.

24. Choi YF, Wong TW, Lau CC. Midazolam is more likely to cause hypotension than etomidate in emergency department rapid sequence intubation. Emerg Med 7 2004;21:700-2, doi:10.1136/emj.2002.004143.

25. Tam AY, Lau FL. A prospective study of tracheal intubation in an emergency department in Hong Kong. Eur 7 Emerg Med 2001;8:305-10, doi:10.1097/00063110-20011200000011

26. Marvez E, Weiss SJ, Houry DE, Ernst AA. Predicting adverse outcomes in a diagnosis-based protocol system for rapid sequence intubation. Am 7 Emerg Med 2003;21:23-9, doi:10.1053/ajem.2003.50002.

27. Wong E, Fong YT, Ho KK. Emergency airway management-experience of a tertiary hospital in South-east Asia. Resuscitation 2004;61:349-55, doi:10.1016/j.resuscitation. 2004.01.011.

28. Wong E, Fong YT. Trauma airway experience by emergency physicians. Eur 7 Emerg Med 2003;10:209-12, doi:10.1097/00063110-200309000-00010.

29. Graham CA, Beard D, Oglesby AJ, et al. Rapid sequence intubation in Scottish urban emergency departments. Emerg Med 7 2003;20:3-5, doi:10.1136/emj.20.1.3.
30. Sivilotti ML, Ducharme J. Randomized, double-blind study on sedatives and hemodynamics during rapid-sequence intubation in the emergency department: the SHRED study Ann Emerg Med 1998;31:313-24, doi:10.1016/S01960644(98)70341-5.

31. Lin CC, Chen KF, Shih CP, et al. The prognostic factors of hypotension after rapid sequence intubation. Am 7 Emerg Med 2008;26:845-51, doi:10.1016/j.ajem.2007.11.027.

32. Omert L, Yeaney W, Mizikowski S, Protetch J. Role of the emergency medicine physician in airway management of the trauma patient. If Trauma 2001;51:1065-8, doi:10.1097/ 00005373-200112000-00007.

33. Li J, Murphy-Lavoie H, Bugas C, et al. Complications of emergency intubation with and without paralysis. Am 7 Emerg Med 1999;17:141-3, doi:10.1016/S0735-6757(99) 90046-3.

34. Levitan RM, Rosenblatt B, Meiner EM, et al. Alternating day emergency medicine and anesthesia resident responsibility for management of the trauma airway: a study of laryngoscopy performance and intubation success. Ann Emerg Med 2004;43:48-53, doi:10.1016/S0196-0644(03)00638-3.

35. Sagarin MJ, Barton ED, Chng YM, Walls RM, National Emergency Airway Registry Investigators. Airway management by US and Canadian emergency medicine residents: a multicenter analysis of more than 6,000 endotracheal intubation attempts. Ann Emerg Med 2005;46:328-36, doi:10.1016/j.annemergmed.2005.01.009.

36. Zed PJ, Abu-Laban RB, Harrison DW. Intubating conditions and hemodynamic effects of etomidate for rapid sequence intubation in the emergency department: an observational cohort study. Acad Emerg Med 2006;13:37883, doi:10.1111/j.1553-2712.2006.tb00313.x.

37. Smith DC, Bergen JM, Smithline H, Kirschner R. A trial of etomidate for rapid sequence intubation in the emergency department. 7 Emerg Med 2000;18:13-6, doi:10.1016/S07364679(99)00154-7.

38. Kovacs G, Law JA, Ross J, et al. Acute airway management in the emergency department by non-anesthesiologists. Can 7 Anaesth 2004;51:174-80, doi:10.1007/BF03018780. 